\title{
Profiles of phenolic compounds in modern and old common wheat varieties determined by liquid chromatography coupled with time-of-flight mass spectrometry
}

\author{
Giovanni Dinelli ${ }^{a}$,*, Antonio Segura-Carretero ${ }^{\mathrm{b}, \mathrm{c}}$, Raffaella Di Silvestro ${ }^{\mathrm{a}}$, Ilaria Marotti ${ }^{\mathrm{a}}$, \\ David Arráez-Román ${ }^{\mathrm{b}, \mathrm{c}}$, Stefano Benedettelli ${ }^{\mathrm{d}}$, Lisetta Ghiselli ${ }^{\mathrm{d}}$, Alberto Fernadez-Gutierrez ${ }^{\mathrm{b}, \mathrm{c}}$ \\ a Department of Agroenvironmental Science and Technology, University of Bologna, viale Fanin, 44, 40127 Bologna, Italy \\ ${ }^{\mathrm{b}}$ Department of Analytical Chemistry, University of Granada, C/Fuentenueva s/n, 18071 Granada, Spain \\ ${ }^{\mathrm{c}}$ Research and Development of Functional Food Centre (CIDAF), Health science Technological park, Avda. Del Conocimiento s/n, 18100, Granada, Spain \\ ${ }^{\mathrm{d}}$ Department of Crop, Soil and Environmental Science, University of Firenze, Firenze, Italy
}

\section{A R T I C L E I N F O}

\section{Article history:}

Available online 27 May 2011

\section{Keywords:}

Wheat

Phytochemicals

Polyphenols

Old varieties

HPLC-TOF-MS

\begin{abstract}
A B S T R A C T
The health-promoting properties of common wheat (Triticum aestivum L.) have been largely attributed to the presence of unique phytochemicals of whole grains. The aim of this study was to profile the phenolic content of 16 old and 6 modern Italian wheat varieties, cropped in the same location and growing season. High variability was observed among the investigated wheat genotypes, both in the free and bound phenolic extracts. The total polyphenol content ranged from 885.5 to $1715.9 \mu \mathrm{mol} \mathrm{GAE} / 100 \mathrm{~g}$ of grain and, on average, the bound fraction contributed for $72.0 \%$ to the total phenolic content. As regards the flavonoid content, the free fraction ranged from 50.7 to $106.1 \mu \mathrm{mol} C \mathrm{C} / 100 \mathrm{~g}$ of grain and the bound fraction from 78.3 to $148.9 \mu \mathrm{mol} \mathrm{CE} / 100 \mathrm{~g}$ of grain. Moreover, the interpretation of the mass spectra allowed the characterization of 34 phenolic compounds (104 including isomer forms) belonging to the phenolic acid, flavonoid, coumarin, stilbene, proanthocyanidin and lignan chemical classes. HPLC-ESI-TOF-MS analysis highlighted remarkable differences in the phytochemical fingerprints of old and modern wheat varieties. Six ancient wheat genotypes (Bianco Nostrale, Frassineto, Gentil Rosso, Gentil Rosso Mutico, Marzuolo d'Aqui, Verna) showed phenolic profiles with a number of total compounds and isomer forms much higher than that identified in the modern cultivars. The present findings confirm that ancient wheat may represent a valuable source of biodiversity, especially as regards phenolic compounds. The investigated old wheat genotypes may be successfully used in breeding programs for developing bread wheat varieties with added value in terms of health-promoting phytochemicals.
\end{abstract}

(C) 2011 Elsevier B.V. All rights reserved.

\section{Introduction}

Common wheat (Triticum aestivum L.) is one of the major crop worldwide and represent the most consumed staple food. Several epidemiological studies indicated that diets rich in wholegrain derived products are associated with decreased incidence of chronic diseases [1-3]. Whole grains contain various phytochemicals in addition to the basic and essential nutrients (proteins, carbohydrates, dietary fiber) and the health benefits have been largely ascribed to the presence of nutraceutics with potential biological activity, such as phenolic compounds. Polyphenols are plant secondary metabolites belonging to the phenylpropanoid pathway that contain one or more aromatic rings and one or more

\footnotetext{
* Corresponding author. Tel.: +39 0512096672; fax: +39 0512096241.

E-mail address: giovanni.dinelli@unibo.it (G. Dinelli).
}

hydroxyl groups, including phenolic acids, coumarins, flavonoids, stilbenes and lignans. Recently, polyphenols have gained attention due to their antioxidant, anti-inflammatory, antimutagenic and anticarcinogenic properties [4,5]. Antioxidants are defined as compounds that, at low concentration, can delay or prevent the oxidative damage of substrates as DNA, enzymes and cell wall molecules, neutralizing free radicals (ROS) that are the cause of many chronic diseases (i.e. cancer and cardiovascular disease). In vitro investigations demonstrated that phenolic compounds possess high antiradical power and contribute to most of the total antioxidant activity of wheat grains [6-9]. Indeed, polyphenols are one of the most complex and representative group of phytochemicals in wheat kernel. They are chiefly concentrated in the outer layers of grains (aleurone and bran cells) and exist as soluble free compounds, soluble conjugates esterified to sugars and other low molecular weight molecules, and insoluble forms bound to cell wall components. The latter are crosslinked with cell wall macromolecules (i.e. arabinoxylans) via ester and ether bonds and 
contribute to the total phenolic content for 60-70\% [7,9]. Previous studies investigated the phenolic content of whole grains and their different fractions (endosperm, aleurone layer, bran) both free and bound forms, mainly using colorimetric methods as spectrophotometrical analyses [6-8]. Recently traditional methods have been replaced by various separation techniques (HPLC, GC, CE) coupled with mass spectrometry (HPLC-MS, GC-MS, CE-MS) as more sensitive tools for the characterization and identification of individual polyphenols in wheat [10-17]. Phenolic acids are the most representative and investigated class of wheat phenolics and their profile has been thoroughly described in recent years [9,12,18-21]. However, literature lacks information about the complete phenolic composition of wheat and of different wheat varieties as regards flavonoid, anthocyanin, stilbene, coumarin and lignan content. In our previous study, the phenolic profile of old and modern durum wheat varieties was investigated using HPLC coupled with time-of-flight mass spectrometry and high qualitative differences were highlighted among the tested genotypes [22]. In particular, old durum wheat varieties showed a qualitative free and bound phenolics content significantly different than those detected in the modern cultivars. This finding suggested that ancient wheat may represent a valuable source of variability for breeding and eventual commercial production of value-added varieties rich in health-beneficial components. Further studies are needed to better understand how these different classes contribute to the maintenance of human health and the synergistic or additive effect among the different classes of phytochemicals. Few authors reported that several factors as genotype, environmental and growing conditions can influence the presence and distribution of phenolic compounds in wheat grains [7,23-26]. However, most literature data concerning wheat phenolic determinations do not give details about field agronomic conditions and growing locations. The present research was conducted to determine and to compare the phenolic composition of different common wheat varieties, including old and modern Italian genotypes, cropped in the same location and growing season. The investigation aims to contribute to the understanding of wheat whole grain nutraceutical properties and promoting the development of wheat varieties with high level of health-promoting phytochemicals.

\section{Materials and methods}

\subsection{Chemicals}

HPLC-grade acetonitrile and methanol was purchased from Labscan (Dublin, Ireland). Acetic acid was of an analytical grade (assay $>99.5 \%$ ) and purchased from Fluka (Switzerland). Water was purified by using a Milli-Q system (Millipore, Bedford, USA). Other reagents unmarked were of an analytical grade.

\subsection{Grain samples and sample preparation}

Wheat samples included 16 old (Andriolo, Autonomia A, Autonomia B, Benco, Bianco Nostrale, Canove, Carosello, Frassineto, Gentil Bianco, Gentil Rosso, Gentil Rosso Mutico, Inallettabile, Marzuolo d'Aqui, Marzuolo Val Pusteria, Sieve, Verna) and 6 modern cultivars (Bilancia, Bolero, Eureka, Mieti, Nobel, Palesio) of common wheat (T. aestivum L.). Seeds from all of the investigated genotypes were grown in the same location at the experimental farm of the University of Bologna, Cadriano (latitude $44^{\circ} 33^{\prime} \mathrm{N}$, longitude $11^{\circ} 21^{\prime} \mathrm{E}, 32 \mathrm{~m}$ a.s.l.), Italy, during the growing season 2006-2007. The soil at the experimental farm of Cadriano is classified as a fine silty, mixed, mesic, Udic stochrepts, and has a silty loam texture, with 380,375 , and $245 \mathrm{~g} / \mathrm{kg}$ of sand, silt, and clay, respectively. The $\mathrm{pH}(1: 2.5$ soil to water) is 7.9 and organic carbon is $8.5 \mathrm{~g} / \mathrm{kg}$. Each genotype was grown in plots $(6 \mathrm{~m} \times 5 \mathrm{~m})$ according to a low input agro-technique (nitrogen fertilization with $10 \mathrm{~kg} \mathrm{NO}_{3} \mathrm{ha}^{-1}$ applied in pre-sowing and $20 \mathrm{~kg} \mathrm{NO}_{3} \mathrm{ha}^{-1}$ applied in leaf sheaths lengthening stage). Weeds were hand controlled and no herbicide (or other pesticide) treatment was applied. Plants were harvested at grain full ripening stage. Whole grain samples were milled to a fine powder, immediately cooled to $-20^{\circ} \mathrm{C}$ and kept at this temperature until analysis to protect bioactive components from degradation.

\subsection{Extraction of soluble and insoluble phenolic compounds}

Free phenolic extraction was performed according to the method described previously $[7,22]$ with some modifications. $1 \mathrm{~g}$ of whole wheat flour was extracted with $20 \mathrm{~mL}$ of $80 \%$ chilled ethanol for $10 \mathrm{~min}$. After centrifugation at $2500 \times \mathrm{g}$ for $10 \mathrm{~min}$, the supernatant was removed and extraction was repeated once. Supernatants were pooled, evaporated to dryness and reconstituted in $10 \mathrm{~mL}$ of $80 \%$ methanol. The extracts were filtered through a $0.22 \mu \mathrm{m}$ filter and stored at $-20^{\circ} \mathrm{C}$ until use. The residue from the free phenolic extraction was subjected to alkaline and acid hydrolysis to recover the bound phenolic compounds as reported by Mattila et al. [18] with some modifications. Briefly, $12 \mathrm{~mL}$ of distilled water and $5 \mathrm{~mL}$ of $10 \mathrm{M} \mathrm{NaOH}$ were added to the residue and stirred overnight at room temperature (about $16 \mathrm{~h}$ ). The solution was then adjusted to a $\mathrm{pH}$ of 2 , and liberated phenolics were extracted three times with $15 \mathrm{~mL}$ of ethyl acetate by manually shaking and centrifuging. Ethyl acetate layers were combined, evaporated to dryness, and dissolved into $10 \mathrm{~mL}$ of methanol. After the above alkaline hydrolysis was completed, an acid hydrolysis was then performed by adding $2.5 \mathrm{~mL}$ of concentrated $\mathrm{HCl}$ into the test tube and incubating the tube in a water bath $\left(85^{\circ} \mathrm{C}\right)$ for $30 \mathrm{~min}$. After acid hydrolysis, the sample was allowed to cool and the ethyl acetate extraction performed in the same manner as after alkaline hydrolysis. Bound phenolic extracts were filtered through a $0.22 \mu \mathrm{m}$ filter and stored at $-20^{\circ} \mathrm{C}$ until use.

\subsection{Determination of total polyphenol and flavonoid contents}

Free and bound polyphenol content of each wheat sample was determined using the Folin-Ciocalteu procedure described by Singleton et al. [27]. Gallic acid was used as the standard and polyphenol content was expressed as micromoles of gallic acid equivalent (GAE) per $100 \mathrm{~g}$ of grain. Free and bound flavonoid content was determined according to a colorimetric method described previously by Adom et al. [7]. Briefly, appropriate dilutions of sample extracts were reacted with sodium nitrite, followed by reaction with aluminium chloride to form a flavonoid-aluminium complex. Solution absorbance at $510 \mathrm{~nm}$ was immediately measured and compared to that of catechin standards. Flavonoid content was expressed as micromoles of catechin equivalent (CE) per $100 \mathrm{~g}$ of grain. Data are reported as mean \pm standard deviation (SD) for six replicates.

\subsection{HPLC-ESI-TOF-MS experimental conditions}

HPLC analysis was performed using an Agilent 1200-RRLC system (Agilent Technologies, CA, USA) consisting of a vacuum degasser, autosampler, a binary pump and a UV-vis detector. Phenolic compounds were separated using a RP C18 analytical column ( $4.6 \mathrm{~mm} \times 150 \mathrm{~mm}, 1.8 \mu \mathrm{m}$ particle size) from Agilent ZORBAX Eclipse plus. The mobile phases and gradient program used were as previously described [22]. The gradient elution was performed with mobile phases consisting of water with acetic acid (0.5\% acetic acid v/v) (A) and acetonitrile (B) as follows: from 5\% to $10 \%$ B in $5 \mathrm{~min}$; from $10 \%$ to $35 \%$ B in $35 \mathrm{~min}$; from $35 \%$ to $70 \%$ 
Table 1

Polyphenol and flavonoid content in cultivar grains, expressed as $\mu$ mol gallic acid equivalent and $\mu$ mol catechin equivalent per $100 \mathrm{~g}$ of whole flour, respectively.

\begin{tabular}{|c|c|c|c|c|c|c|}
\hline Cultivar & FPC & $\mathrm{BPC}$ & TPC & FFC & $\mathrm{BFC}$ & TFC \\
\hline Andriolo $(\mathrm{O})$ & $262.4(\mathrm{jk})$ & $609.9(\mathrm{i})$ & $872.2(\mathrm{j})$ & $86.0(b c)$ & 97.7 (hi) & 183.7 (efg) \\
\hline Autonomia A (O) & 326.1 (ghi) & 914.4 (efgh) & 1240.5 (fgh) & 64.6 (efgh) & 103.7 (ghi) & 168.3 (fghi) \\
\hline Autonomia B (O) & 307.5 (hi) & $793.2(\mathrm{~h})$ & $1100.7(\mathrm{i})$ & 69.1 (defg) & $78.3(\mathrm{j})$ & $147.4(\mathrm{j})$ \\
\hline Benco $(0)$ & $243.0(\mathrm{k})$ & 642.5 (i) & $885.5(\mathrm{j})$ & 64.8 (efgh) & 117.6 (defg) & 182.4 (efg) \\
\hline Bianco Nostrale $(\mathrm{O})$ & 326.9 (ghi) & 984.3 (de) & 1311.2 (efg) & $50.7(\mathrm{i})$ & 103.2 (ghi) & $153.8(\mathrm{ij})$ \\
\hline Bilancia (M) & $410.8(\mathrm{de})$ & 832.0 (gh) & 1242.8 (fgh) & $77.5(\mathrm{~cd})$ & $98.2(\mathrm{hi})$ & 175.7 (efgh) \\
\hline Bolero (M) & $354.1(\mathrm{fg})$ & $794.8(\mathrm{~h})$ & $1148.8(\mathrm{hi})$ & 73.3 (de) & $93.2(\mathrm{ij})$ & 166.5 (ghi) \\
\hline Canove (O) & $438.0(\mathrm{~cd})$ & 954.8 (defg) & $1392.8(\mathrm{de})$ & 56.4 (hi) & 111.6 (efgh) & 168.0 (fghi) \\
\hline Carosello (O) & $470.6(\mathrm{bc})$ & 1082.2 (bcd) & $1552.8(\mathrm{bc})$ & 62.4 (efgh) & 121.1 (def) & 183.4 (efg) \\
\hline Eureka (M) & 386.7 (ef) & $1187.9(\mathrm{ab})$ & $1574.5(\mathrm{bc})$ & $73.0(\mathrm{de})$ & $134.5(\mathrm{abcd})$ & $207.6(b c)$ \\
\hline Frassineto $(\mathrm{O})$ & 381.3 (ef) & 846.0 (fgh) & 1227.3 (ghi) & 64.6 (efgh) & 104.7 (fghi) & 169.3 (fghi) \\
\hline Gentil Bianco (O) & 342.4 (ghi) & 1044.9 (cde) & 1387.3 (de) & 63.6 (efgh) & 124.1 (cde) & 187.7 (def) \\
\hline Gentil Rosso (O) & $419.3(\mathrm{de})$ & $1226.7(\mathrm{a})$ & $1646.0(\mathrm{ab})$ & 63.3 (efgh) & $148.9(\mathrm{a})$ & $212.3(\mathrm{bc})$ \\
\hline Gentil Rosso Mutico (O) & $442.6(\mathrm{~cd})$ & 1009.2 (cde) & 1451.8 (cde) & $92.2(\mathrm{~b})$ & $142.5(\mathrm{ab})$ & $234.7(a)$ \\
\hline Inallettabile $(\mathrm{O})$ & 344.0 (fgh) & $1060.4(\mathrm{bcd})$ & 1404.4 (de) & $77.0(\mathrm{~cd})$ & 129.5 (bcd) & 206.6 (bcd) \\
\hline Marzuolo d'Aqui (O) & $450.4(\mathrm{~cd})$ & $1125.7(\mathrm{abc})$ & $1576.1(\mathrm{bc})$ & $90.0(\mathrm{~b})$ & 123.1 (cde) & $213.0(b c)$ \\
\hline Marzuolo Val Pusteria (O) & $292.7(\mathrm{ij})$ & $1060.4(\mathrm{bcd})$ & 1353.1 (defg) & 72.1 (def) & 139.5 (abc) & $211.5(\mathrm{bc})$ \\
\hline Mieti (M) & 381.3 (ef) & $985.9(\mathrm{de})$ & 1367.1 (def) & 58.6 (ghi) & 103.2 (ghi) & 161.8 (hij) \\
\hline Nobel (M) & 316.0 (ghi) & $1237.6(a)$ & $1553.6(\mathrm{bc})$ & $61.4(\mathrm{fgh})$ & $132.5(\mathrm{abcd})$ & 193.9 (cde) \\
\hline Palesio (M) & 346.3 (fgh) & 1007.6 (cde) & 1353.9 (defg) & 69.1 (defg) & $97.7(\mathrm{hi})$ & 166.8 (ghi) \\
\hline Sieve $(0)$ & 498.6 (b) & 964.1 (def) & $1462.7(\mathrm{~cd})$ & $92.7(\mathrm{~b})$ & 100.7 (ghi) & 193.4 (cde) \\
\hline Verna $(0)$ & $579.4(a)$ & $1136.6(\mathrm{abc})$ & $1715.9(a)$ & $106.1(a)$ & 107.7 (efghi) & $213.8(b)$ \\
\hline Mean value & 378.2 & 977.3 & 1355.5 & 72.2 & 114.2 & 186.4 \\
\hline
\end{tabular}

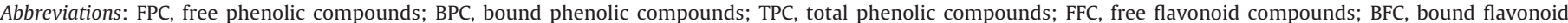
compounds; TFC, total flavonoid compounds; M, modern cultivar; O, old cultivar.

Means followed by the same letter or no letter are not significantly different at $P<0.05$.

B in $20 \mathrm{~min}$; from $70 \%$ to $95 \%$ B in 2 min; from $95 \%$ to $5 \%$ B in $2 \mathrm{~min}$. An 8 min re-equilibration time was used after each analysis. The flow rate was set at $0.50 \mathrm{~mL} / \mathrm{min}$ throughout the gradient. The effluent from the HPLC column was splitted using a T-type phase separator before being introduced into the mass spectrometer ( split ratio $=1: 3$ ). Thus in this study the flow which arrived into the MS detector was $0.125 \mathrm{~mL} / \mathrm{min}$. The column temperature was maintained at $40^{\circ} \mathrm{C}$ and the injection volume was $10 \mu \mathrm{L}$. The HPLC system was coupled to a microTOF (Bruker Daltonics, Bremen, Germany), an orthogonal-accelerated TOF mass spectrometer (oaTOFMS), equipped with an ESI interface. Parameters for analysis were set using negative ion mode with spectra acquired over a mass range from $\mathrm{m} / \mathrm{z} 50$ to 1000 . The optimum values of the ESI-MS parameters were: capillary voltage, $+4.5 \mathrm{kV}$; drying gas temperature, $190^{\circ} \mathrm{C}$; drying gas flow, $7.0 \mathrm{~L} / \mathrm{min}$; and nebulizing gas pressure, 2 bar. The accurate mass data of the molecular ions were processed through the newest software Data Analysis 4.0 (Bruker Daltonics, Bremen, Germany), which provided a list of possible elemental formula by using the Smart Formula Editor. The Editor uses a CHNO algorithm, which provides standard functionalities such as minimum/maximum elemental range, electron configuration, and ring-plus double bonds equivalents, as well as a sophisticated comparison of the theoretical with the measured isotope pattern (sigma value) for increased confidence in the suggested molecular formula. The widely accepted accuracy threshold for confirmation of elemental compositions has been established at $5 \mathrm{ppm}$. We also have to say that even with very high mass accuracy $(<1 \mathrm{ppm})$ many chemically possible formulae are obtained depending on the mass regions considered. So, high mass accuracy ( $<1 \mathrm{ppm})$ alone is not enough to exclude enough candidates with complex elemental compositions. The use of isotopic abundance patterns as a single further constraint removes $>95 \%$ of false candidates. This orthogonal filter can condense several thousand candidates down to only a small number of molecular formulae. During the development of the HPLC method, external instrument calibration was performed using a Cole Palmer syringe pump (Vernon Hills, Illinois, USA) directly connected to the interface, passing a solution of sodium formate cluster containing $5 \mathrm{mM}$ sodium hydroxide in the sheath liquid of $0.2 \%$ formic acid in water/isopropanol $1: 1(\mathrm{v} / \mathrm{v})$.
Using this method, an exact calibration curve based on numerous cluster masses each differing by $68 \mathrm{Da}\left(\mathrm{NaCHO}_{2}\right)$ was obtained. Due to the compensation of temperature drift in the microTOF, this external calibration provided accurate mass values (better $5 \mathrm{ppm}$ ) for a complete run without the need for a dual sprayer setup for internal mass calibration.

\subsection{Statistical analysis}

One-way analysis of variance (ANOVA, Tukey's honest significant difference multiple comparison) was evaluated using Statistica 6.0 software (2001, StatSoft, Tulsa, OK, USA). Phenolic compound data were processed according to the correspondence analysis [28]. Correspondence analysis is a statistical visualization method for picturing the association between the levels of a two-way contingency table. The contingency table was prepared excluding the isomers out of the 104 identified compounds. For each of the remaining 34 compounds the relative isomer abundance in the wheat varieties was computed. The plotting in the first two dimensions of the coordinates of row (wheat genotypes) and column (phytochemicals) variables permitted to have a global view of the correspondence between variety distribution and the factor axis. In the biplot only the phytochemicals with high variation distribution were represented. The first and second dimensions explained 38 and $32 \%$ of total variability, respectively.

\section{Results and discussion}

\subsection{Polyphenol and flavonoid content of wheat varieties}

Polyphenols are a large group of phytochemicals including flavonoids, the most representative in wheat kernel. Phenolics are chiefly concentrated in the outer layers of wheat grains (bran and aleurone) and contribute to the wheat flour nutraceutical value arising from their antioxidant, anti-inflammatory and anticancer properties [8]. The determination of phenolic content of whole grains evidenced high variability among the 16 old and 6 modern investigated wheat genotypes. The polyphenol content (free and bound fractions) of each wheat variety is presented in Table 1 

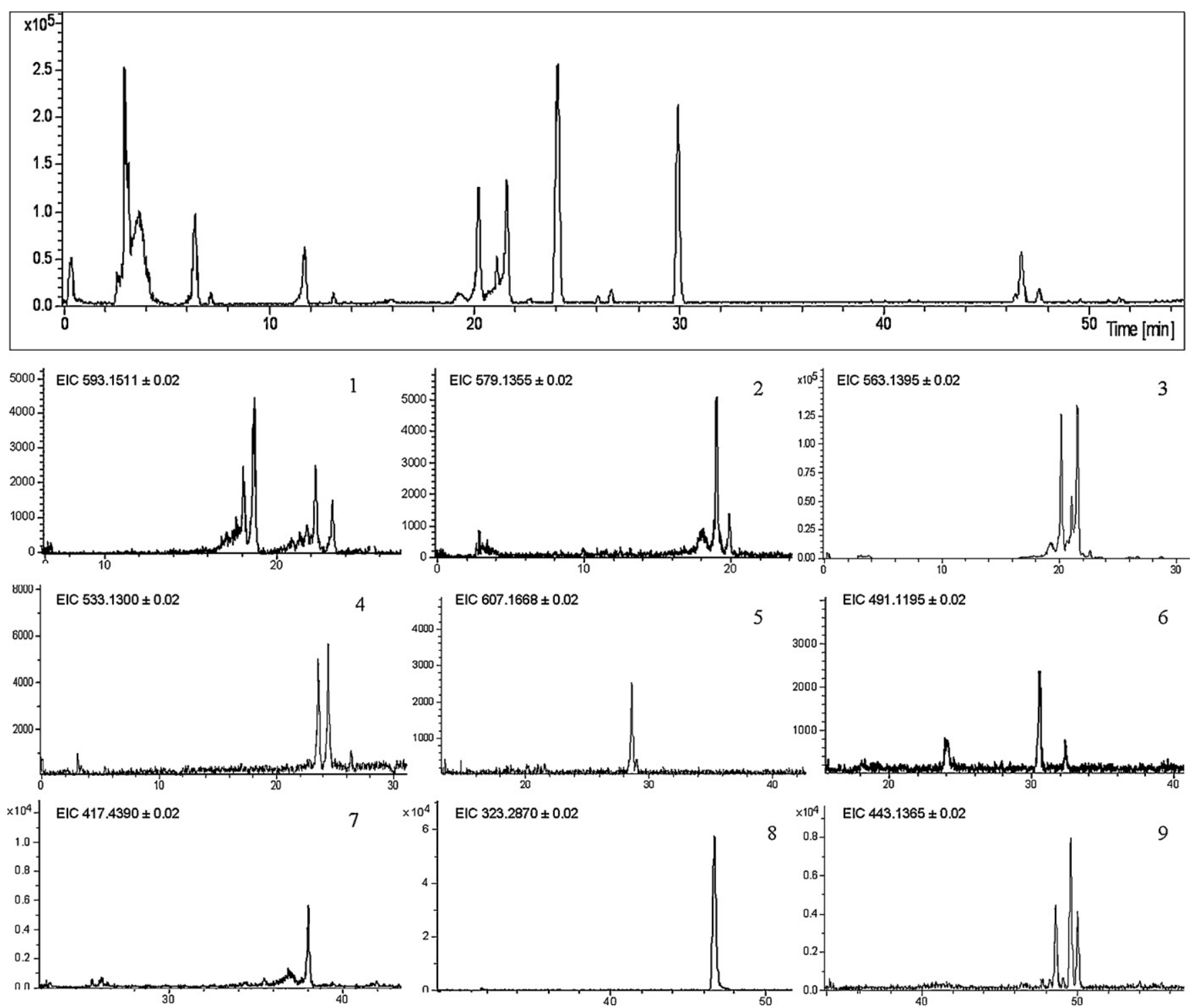

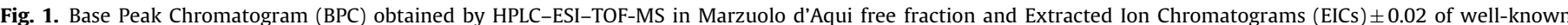

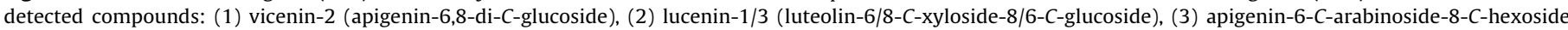

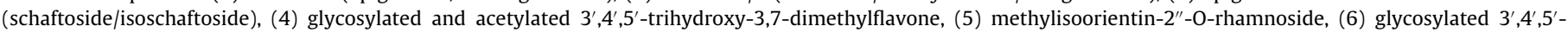
trihydroxy-3,7-dimethylflavone, (7) syringaresinol, (8) anthocyanidin (cyanidin chloride), (9) formononetin (glycosylated and methylated).

and expressed as micromoles of gallic acid equivalent (GAE) per $100 \mathrm{~g}$ of grain. Free polyphenol content ranged from $579.4 \mu \mathrm{mol}$ $\mathrm{GAE} / 100 \mathrm{~g}$ of grain in Verna to $243.0 \mu \mathrm{mol} \mathrm{GAE} / 100 \mathrm{~g}$ of grain in Benco, and a mean value of $378.2 \mu \mathrm{mol} \mathrm{GAE} / 100 \mathrm{~g}$ was obtained (Table 1). Along with Verna, other five old wheat varieties (Canove, Carosello, Gentil Rosso, Gentil Rosso Mutico, Sieve) showed an elevated free polyphenol content, higher than the obtained mean value. As regards the bound fraction, phenolic content ranged from $1237.6 \mu \mathrm{mol} \mathrm{GAE} / 100 \mathrm{~g}$ of grain (Nobel) to $609.9 \mu \mathrm{mol} \mathrm{GAE} / 100 \mathrm{~g}$ of grain (Andriolo). The old genotypes Carosello, Gentil Rosso, Inallettabile, Marzuolo d'Aqui, Marzuolo Val Pusteria and Verna were the highest in terms of bound polyphenol content, along with the modern varieties Eureka and Nobel. On average, the bound fraction contributed to the total phenolic content for $72.0 \%$, confirming previous findings that in wheat kernel polyphenols primarily exist in the bound form, associated with cell wall components $[7,9,29]$. Flavonoid content of the wheat samples is presented in Table 1 and expressed as micromoles of catechin equivalent (CE) per $100 \mathrm{~g}$ of grain. Significantly different values were observed among the 22 tested wheat varieties in the free, bound and total flavonoid fractions. Free flavonoid content ranged from $106.1 \pm 0.4$ (Verna) to $50.7 \pm 6.3$ (Bianco Nostrale) $\mu \mathrm{mol} \mathrm{CE} / 100 \mathrm{~g}$ of grain. The old genotypes Andriolo, Gentil Rosso Mutico, Marzuolo d'Aqui, Sieve and Verna showed the higher free flavonoid content. The bound flavonoid content ranged from $148.9 \pm 4.2$ (Gentil Rosso) to $78.3 \pm 0.1$ (Autonomia B) $\mu \mathrm{mol} \mathrm{CE} / 100 \mathrm{~g}$ of grain. The highest values of bound flavonoids were observed for the old genotypes Gentil Rosso, Gentil Rosso Mutico, Inallettabile, Marzuolo d'Aqui and Marzuolo Val Pusteria, along with the modern varieties Eureka and Nobel. The bound fraction contributed to the total flavonoid content for $61.2 \%$. Previous studies investigated the free and bound phenolic content in diverse common wheat varieties. In our study, high variability was observed among the 22 wheat samples and total polyphenol and flavonoid amounts of several genotypes resulted higher compared to data previously reported, especially as regards the bound fraction $[7,9,30]$. Both genotype and environmental conditions have been demonstrated to affect the phenolic content of wheat grains. Previous investigations reported on highly significant differences of polyphenol content among different wheat varieties, suggesting the genotype-specificity of this characteristic. More- 
over the comparison of wheat cultivars grown at different locations showed that environmental and growing conditions may have a certain effect on the biosynthesis and accumulation of phenolic compounds [23-26]. Further studies are necessary to better understand the interaction between genotype and environment with the aim to identify wheat varieties that, at certain growing conditions, may provide wheat-based food products with high nutraceutical value.

\subsection{HPLC-ESI-TOF-MS optimization and identification of phenolic compounds}

The free phenolic extract of the Marzuolo d'Aqui variety was used to optimize the chromatographic and MS conditions.

Several preliminary experiments were performed testing different mobile phases. A solvent system consisting of acetonitrile of $0.5 \%$ acetic acid aqueous solution and acetonitrile was ultimately selected, providing lower pressure, greater baseline stability and higher ionization efficiency. Flow rate is a key factor for separation when using short columns packed with 1.7-2.5 $\mu \mathrm{m}$ particles. Selection of optimum flow rate is based on a compromise between the speed, separation efficiency, peak width and column backpressure. The flow rate of $0.5 \mathrm{~mL} / \mathrm{min}$ adopted in this method produced a relative short analytical time of less than $50 \mathrm{~min}$ and moderate column pressure at about 125 bar for the Marzuolo d'Aqui sample.

Many phenolic compounds in wheat have isomers and are difficult to be separated due to their extremely similar structures. The chromatographic separation of those compounds, having the same molecular weight, is important as single-stage TOF/MS does not distinguish coeluting compounds. Thus, gradient elution was applied to improve the separation of the extracts by varying the solvent strength during the elution process and the optimum gradient was finally picked out through a large number of empirical attempts.

Tentative characterization of phenolic compounds, free and bound, were generated based on elemental composition data determined from accurate mass measurements and comparison with literature data. Fig. 1 shows the base peak chromatogram (BPC) for the free phenolic fraction of the wheat sample Marzuolo d'Aqui and the extracted ion chromotograms (EICs) for the main characterized compounds. All the polyphenols detected for Marzuolo d'Aqui free extract are summarized in Table 2. This table includes selected ion, tolerance $(\mathrm{ppm})$ in generated molecular formula, molecular formula, $m / z$ experimental, error, sigma values and retention time. The characterization by TOF (MS) was carried out using the Generate Molecular Formula Editor. First of all, a low tolerance was chosen $(5 \mathrm{ppm})$. After that, options with a low sigma value $(<0.05)$ and a low error $(<5 \mathrm{ppm})$ were taken into account in most cases. Finally, the position of the molecular formula in the list of possible compounds was considered. Table 3 lists the phenolic compounds detected in the free and bound extracts of all the wheat varieties. The interpretation of mass spectra allowed the identification of 34 phenolic compounds (104 including isomer forms) in the 22 investigated genotypes. Most of the detected polyphenols were previously described in wheat in other reports [13,14,16,17,31,32]. As outlined below, compounds were grouped into chemical classes and structural formulae of representative compounds are shown in Fig. 2. The phenolic compounds (including isomers) were numbered according to the retention time and their occurrence in the common wheat genotypes is presented in Table 3.

\subsubsection{Phenolic acids}

Several studies investigated the phenolic acid composition of wheat grains and of different seed parts (endosperm, bran and aleurone layer) $[7,10,12,18-20,29,33]$. In wheat, ferulic acid is the predominant compound of the class and accounts for $70-90 \%$ of total phenolic acid content $[18,24]$. Ferulic acid can be found in

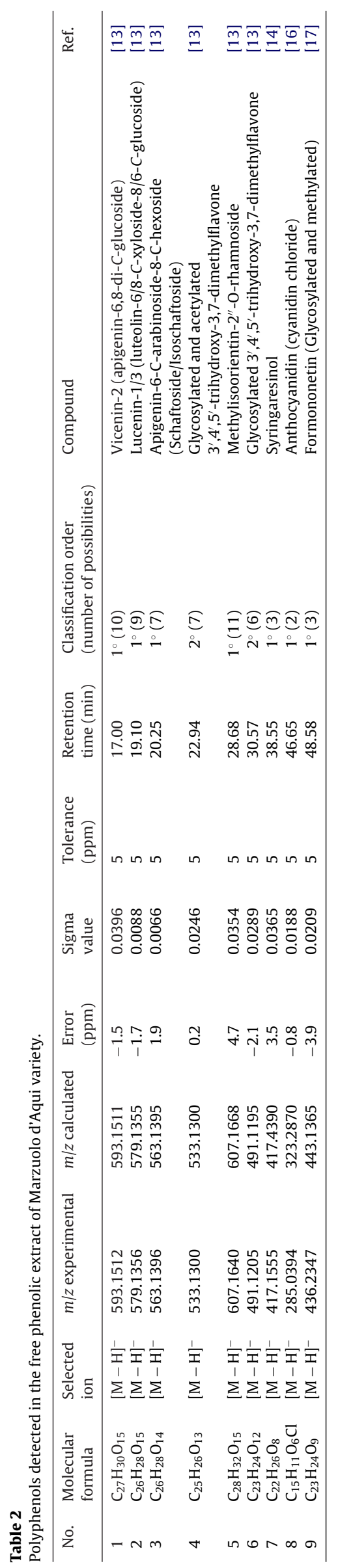


Table 3

Phenolic compounds detected by HPLC-ESI-TOF-MS in the free and bound extracts of wheat varieties.

\begin{tabular}{|c|c|c|c|c|c|c|c|c|}
\hline \multirow[t]{2}{*}{ No. } & \multirow{2}{*}{$\begin{array}{l}\text { Retention } \\
\text { time (min) }\end{array}$} & \multirow{2}{*}{$\begin{array}{l}\text { Molecular } \\
\text { formula }\end{array}$} & \multirow[t]{2}{*}{$\mathrm{m} / \mathrm{z}$ calculated } & \multirow[t]{2}{*}{ Compound } & \multirow[t]{2}{*}{ Class } & \multicolumn{2}{|l|}{ Sample } & \multirow[t]{2}{*}{ Reference } \\
\hline & & & & & & Free extract & Bound extract & \\
\hline 1 & 10.92 & $\mathrm{C}_{9} \mathrm{H}_{10} \mathrm{O}_{5}$ & 197.0455 & Syringic acid isomer & Phenolic acids & BO & & [31] \\
\hline 2 & 12.73 & $\mathrm{C}_{10} \mathrm{H}_{10} \mathrm{O}_{4}$ & 193.0506 & Ferulic acid & Phenolic acids & AA AB CAR & AN AB CAR GR NO & [31] \\
\hline 3 & 13.58 & $\mathrm{C}_{10} \mathrm{H}_{10} \mathrm{O}_{4}$ & 193.0506 & Ferulic acid isomer & Phenolic acids & & AN AA AB CAR NO & [31] \\
\hline 4 & 15.43 & $\mathrm{C}_{8} \mathrm{H}_{8} \mathrm{O}_{4}$ & 167.0349 & Vanillic acid & Phenolic acids & BE CAR EU & AB BE BN CAR GR GRM MA & [31] \\
\hline 5 & 16.23 & $\mathrm{C}_{27} \mathrm{H}_{30} \mathrm{O}_{15}$ & 593.1511 & Vicenin-2 (apigenin-6,8-di-C-glucoside) isomer & Flavone-C-glycoside & GR & & [13] \\
\hline 6 & 16.69 & $\mathrm{C}_{9} \mathrm{H}_{10} \mathrm{O}_{5}$ & 197.0455 & Syringic acid & Phenolic acids & BO & $\begin{array}{l}\text { AN AA AB BN BI BO CAN CAR EU } \\
\text { FR GR GRM IN PA }\end{array}$ & [31] \\
\hline 7 & 17.00 & $\mathrm{C}_{27} \mathrm{H}_{30} \mathrm{O}_{15}$ & 593.1511 & Vicenin-2 (apigenin-6,8-di-C-glucoside) isomer & Flavone-C-glycoside & GR MA & & [13] \\
\hline 8 & 17.32 & $\mathrm{C}_{7} \mathrm{H}_{6} \mathrm{O}_{2}$ & 121.0290 & p-Hydroxybenzaldehyde & Phenolic acids & & BI FR IN MA MVP PA & [31] \\
\hline 9 & 17.44 & $\mathrm{C}_{26} \mathrm{H}_{28} \mathrm{O}_{15}$ & 579.1355 & Lucenin-1/3 (luteolin-6/8-C-xyloside-8/6-C-glucoside) isomer & Flavone-C-glycoside & BI GR & & [13] \\
\hline 10 & 17.83 & $\mathrm{C}_{8} \mathrm{H}_{8} \mathrm{O}_{4}$ & 167.0349 & Vanillic acid isomer & Phenolic acids & $\mathrm{EU}$ & & [31] \\
\hline 11 & 18.10 & $\mathrm{C}_{27} \mathrm{H}_{30} \mathrm{O}_{15}$ & 593.1511 & Vicenin-2 (apigenin-6,8-di-C-glucoside) isomer & Flavone-C-glycoside & MA VE & & [13] \\
\hline 12 & 18.22 & $\mathrm{C}_{26} \mathrm{H}_{28} \mathrm{O}_{15}$ & 579.1355 & Lucenin-1/3 (luteolin-6/8-C-xyloside-8/6-C-glucoside) isomer & Flavone-C-glycoside & GR & & [13] \\
\hline 13 & 18.51 & $\mathrm{C}_{27} \mathrm{H}_{30} \mathrm{O}_{15}$ & 593.1511 & Vicenin-2 (apigenin-6,8-di-C-glucoside) isomer & Flavone-C-glycoside & GRM MVP & & [13] \\
\hline 14 & 18.57 & $\mathrm{C}_{26} \mathrm{H}_{28} \mathrm{O}_{14}$ & 563.1395 & $\begin{array}{l}\text { Apigenin-6-C-arabinoside-8-C-hexoside } \\
\text { (Schaftoside/Isoschaftoside) isomer }\end{array}$ & Flavone-C-glycoside & BI GR & BI & [13] \\
\hline 15 & 18.80 & $\mathrm{C}_{27} \mathrm{H}_{30} \mathrm{O}_{15}$ & 593.1511 & Vicenin-2 (apigenin-6,8-di-C-glucoside) isomer & Flavone-C-glycoside & GRM MA MVP & & [13] \\
\hline 16 & 19.10 & $\mathrm{C}_{26} \mathrm{H}_{28} \mathrm{O}_{15}$ & 579.1355 & Lucenin-1/3 (luteolin-6/8-C-xyloside-8/6-C-glucoside) & Flavone-C-glycoside & GRM MA MVP VE & BN FR & [13] \\
\hline 17 & 19.90 & $\mathrm{C}_{26} \mathrm{H}_{28} \mathrm{O}_{14}$ & 563.1395 & $\begin{array}{l}\text { Apigenin-6-C-arabinoside-8-C-hexoside } \\
\text { (Schaftoside/Isoschaftoside) isomer }\end{array}$ & Flavone-C-glycoside & GR & BI & [13] \\
\hline 18 & 19.97 & $\mathrm{C}_{26} \mathrm{H}_{28} \mathrm{O}_{15}$ & 579.1355 & Lucenin-1/3 (luteolin-6/8-C-xyloside-8/6-C-glucoside) isomer & Flavone-C-glycoside & VE & & [13] \\
\hline 19 & 20.25 & $\mathrm{C}_{26} \mathrm{H}_{28} \mathrm{O}_{14}$ & 563.1395 & $\begin{array}{l}\text { Apigenin-6-C-arabinoside-8-C-hexoside } \\
\text { (Schaftoside/Isoschaftoside) isomer }\end{array}$ & Flavone-C-glycoside & GR GRM MA MVP VE & EU FR GR MA MVP SI VE & [13] \\
\hline 20 & 20.62 & $\mathrm{C}_{27} \mathrm{H}_{30} \mathrm{O}_{15}$ & 593.1511 & Vicenin-2 (apigenin-6,8-di-C-glucoside) isomer & Flavone-C-glycoside & GR & & [13] \\
\hline 21 & 20.90 & $\mathrm{C}_{27} \mathrm{H}_{30} \mathrm{O}_{15}$ & 625.1411 & Apigenin-6/8-C-pentoside-8/6-C-hexoside & Flavone-C-glycoside & & $\mathrm{BI}$ & [13] \\
\hline 22 & 21.14 & $\mathrm{C}_{26} \mathrm{H}_{28} \mathrm{O}_{14}$ & 563.1395 & $\begin{array}{l}\text { Apigenin-6-C-arabinoside-8-C-hexoside } \\
\text { (Schaftoside/Isoschaftoside) isomer }\end{array}$ & Flavone-C-glycoside & MA MVP VE & & [13] \\
\hline 23 & 21.60 & $\mathrm{C}_{26} \mathrm{H}_{28} \mathrm{O}_{14}$ & 563.1395 & $\begin{array}{l}\text { Apigenin-6-C-arabinoside-8-C-hexoside } \\
\text { (Schaftoside/Isoschaftoside) }\end{array}$ & Flavone-C-glycoside & $\begin{array}{l}\text { FR GRM MA MVP PA } \\
\text { VE }\end{array}$ & EU FR GB MA PA SI & [13] \\
\hline 24 & 21.80 & $\mathrm{C}_{27} \mathrm{H}_{30} \mathrm{O}_{15}$ & 593.1511 & Vicenin-2 (apigenin-6,8-di-C-glucoside) isomer & Flavone-C-glycoside & GR MVP VE & & [13] \\
\hline 25 & 22.08 & $\mathrm{C}_{25} \mathrm{H}_{26} \mathrm{O}_{13}$ & 533.1300 & $\begin{array}{l}\text { Glycosylated and acetylated } \\
3^{\prime}, 4^{\prime}, 5^{\prime} \text {-trihydroxy-3,7-dimethylflavone isomer }\end{array}$ & Flavone-O-glycoside & GR & & [13] \\
\hline 26 & 22.27 & $\mathrm{C}_{27} \mathrm{H}_{30} \mathrm{O}_{15}$ & 593.1511 & Vicenin-2 (apigenin-6,8-di-C-glucoside) isomer & Flavone-C-glycoside & FR MVP & & [13] \\
\hline 27 & 22.68 & $\mathrm{C}_{26} \mathrm{H}_{28} \mathrm{O}_{14}$ & 563.1395 & $\begin{array}{l}\text { Apigenin-6-C-arabinoside-8-C-hexoside } \\
\text { (Schaftoside/Isoschaftoside) isomer }\end{array}$ & Flavone-C-glycoside & GRM PA & & [13] \\
\hline 28 & 22.94 & $\mathrm{C}_{25} \mathrm{H}_{26} \mathrm{O}_{13}$ & 533.1300 & $\begin{array}{l}\text { Glycosylated and acetylated } \\
3^{\prime}, 4^{\prime}, 5^{\prime} \text {-trihydroxy-3,7-dimethylflavone }\end{array}$ & Flavone-O-glycoside & GR MA VE & BO NO & [13] \\
\hline 29 & $22.98 / 23.00$ & $\mathrm{C}_{8} \mathrm{H}_{8} \mathrm{O}_{3}$ & 151.0400 & Vanillin & Phenolic acids & & CAN CAR EU GRM IN MA SI & [31] \\
\hline 30 & 23.09 & $\mathrm{C}_{26} \mathrm{H}_{32} \mathrm{O}_{12}$ & 535.1821 & Pinosylvin (double glycosylation) & Stilbenoids & GR & & [17] \\
\hline 31 & 23.20 & $\mathrm{C}_{9} \mathrm{H}_{6} \mathrm{O}_{2}$ & 145.0295 & Coumarin & Coumarins (lactones) & & GRM MA & [31] \\
\hline 32 & 23.30 & $\mathrm{C}_{27} \mathrm{H}_{30} \mathrm{O}_{15}$ & 593.1511 & Vicenin-2 (apigenin-6,8-di-C-glucoside) isomer & Flavone-C-glycoside & MA MVP VE & & [13] \\
\hline 33 & 23.63 & $\mathrm{C}_{9} \mathrm{H}_{8} \mathrm{O}_{3}$ & 163.0400 & p-Coumaric acid & Phenolic acids & & $\begin{array}{l}\text { AN AA AB BN BO CAN GRM IN } \\
\text { MA SI }\end{array}$ & [31] \\
\hline 34 & 24.25 & $\mathrm{C}_{9} \mathrm{H}_{10} \mathrm{O}_{4}$ & 181.0506 & Syringaldehyde & Phenolic acids & & AN AA BO CAN CAR GRM IN VE & [31] \\
\hline 35 & 24.30 & $\mathrm{C}_{26} \mathrm{H}_{32} \mathrm{O}_{12}$ & 535.1821 & Pinosylvin (double glycosylation) isomer & Stilbenoids & & GR & [17] \\
\hline 36 & 24.50 & $\mathrm{C}_{25} \mathrm{H}_{26} \mathrm{O}_{13}$ & 533.1300 & $\begin{array}{l}\text { Glycosylated and acetylated } \\
3^{\prime}, 4^{\prime}, 5^{\prime} \text {-trihydroxy-3,7-dimethylflavone isomer }\end{array}$ & Flavone-O-glycoside & MA VE & & [13] \\
\hline 37 & 24.88 & $\mathrm{C}_{21} \mathrm{H}_{20} \mathrm{O}_{10}$ & 431.0983 & Vitexin/Isovitexin & Flavone-C-glycoside & GRM SI & BN BI MVP NO & [13] \\
\hline 38 & 24.92 & $\mathrm{C}_{10} \mathrm{H}_{10} \mathrm{O}_{4}$ & 193.0506 & Ferulic acid isomer & Phenolic acids & AA AB CAR & $\begin{array}{l}\text { AN AA AB BE BN BI BO CAN CAR } \\
\text { GR GRM MA MI NO PA }\end{array}$ & [31] \\
\hline 39 & 25.00 & $\mathrm{C}_{27} \mathrm{H}_{30} \mathrm{O}_{15}$ & 593.1511 & Vicenin-2 (apigenin-6,8-di-C-glucoside) isomer & Flavone-C-glycoside & VE GR & CAN CAR EU FR SI & [13] \\
\hline 40 & 25.20 & $\mathrm{C}_{27} \mathrm{H}_{30} \mathrm{O}_{15}$ & 593.1511 & Vicenin-2 (apigenin-6,8-di-C-glucoside) & Flavone-C-glycoside & VE GR & CAN CAR EU FR SI & [13] \\
\hline 41 & 25.67 & $\mathrm{C}_{10} \mathrm{H}_{10} \mathrm{O}_{4}$ & 193.0506 & Ferulic acid isomer & Phenolic acids & $\mathrm{AB}$ & CAN NO & [31] \\
\hline 42 & 25.71 & $\mathrm{C}_{11} \mathrm{H}_{12} \mathrm{O}_{5}$ & 223.0612 & Sinapic acid & Phenolic acids & & CAR & [31] \\
\hline
\end{tabular}




\begin{tabular}{|c|c|c|c|c|}
\hline 43 & 25.90 & $\mathrm{C}_{22} \mathrm{H}_{23} \mathrm{O}_{11} \mathrm{Cl}$ & 461.1089 & Peonidin-3-glucoside \\
\hline 44 & 26.00 & $\mathrm{C}_{33} \mathrm{H}_{38} \mathrm{O}_{21}$ & 769.1821 & $\begin{array}{l}\text { Apigenin-6-C-beta-galactosyl-8-C-beta-glucosyl-0- } \\
\text { glucuronopyranoside }\end{array}$ \\
\hline 45 & 26.60 & $\mathrm{C}_{33} \mathrm{H}_{38} \mathrm{O}_{21}$ & 769.1821 & $\begin{array}{l}\text { Apigenin-6-C-beta-galactosyl-8-C-beta-glucosyl-O- } \\
\text { glucuronopyranoside } \\
\text { isomer }\end{array}$ \\
\hline 46 & 26.65 & $\mathrm{C}_{21} \mathrm{H}_{21} \mathrm{O}_{10} \mathrm{Cl}$ & 433.2710 & Pelargonidin-3-glucoside (callistephin) \\
\hline 47 & 26.70 & $\mathrm{C}_{15} \mathrm{H}_{10} \mathrm{O}_{5}$ & 269.0455 & Apigenin \\
\hline 48 & 26.75 & $\mathrm{C}_{21} \mathrm{H}_{20} \mathrm{O}_{10}$ & 431.0983 & Vitexin/Isovitexin isomer \\
\hline 49 & 27.50 & $\mathrm{C}_{10} \mathrm{H}_{10} \mathrm{O}_{4}$ & 193.0506 & Ferulic acid isomer \\
\hline 50 & 27.56 & $\mathrm{C}_{28} \mathrm{H}_{32} \mathrm{O}_{15}$ & 607.1668 & Methylisoorientin-2"-O-rhamnoside isomer \\
\hline 51 & 27.90 & $\mathrm{C}_{27} \mathrm{H}_{30} \mathrm{O}_{14}$ & 577.1562 & Isovitexin-2"-0-rhamnoside \\
\hline 52 & 28.00 & $\mathrm{C}_{15} \mathrm{H}_{10} \mathrm{O}_{5}$ & 269.0455 & Apigenin isomer \\
\hline 53 & 28.12 & $\mathrm{C}_{22} \mathrm{H}_{26} \mathrm{O}_{8}$ & 417.4390 & Syringaresinol isomer \\
\hline 54 & 28.63 & $\mathrm{C}_{21} \mathrm{H}_{22} \mathrm{O}_{8}$ & 401.1241 & Glycosylated pinosylvin \\
\hline 55 & 28.68 & $\mathrm{C}_{28} \mathrm{H}_{32} \mathrm{O}_{15}$ & 607.1668 & Methylisoorientin-2"-0-rhamnoside \\
\hline 56 & 28.72 & $\mathrm{C}_{33} \mathrm{H}_{38} \mathrm{O}_{21}$ & 769.1821 & $\begin{array}{l}\text { Apigenin-6-C-beta-galactosyl-8-C-beta-glucosyl-0- } \\
\text { glucuronopyranoside } \\
\text { isomer }\end{array}$ \\
\hline 57 & 29.00 & $\mathrm{C}_{21} \mathrm{H}_{20} \mathrm{O}_{11}$ & 447.3800 & Orientin/Isoorientin \\
\hline 58 & 29.07 & $\mathrm{C}_{21} \mathrm{H}_{21} \mathrm{O}_{11} \mathrm{Cl}$ & 447.0932 & Cyanidin-3-glucoside (kuromanin) \\
\hline 59 & 29.12 & $\mathrm{C}_{20} \mathrm{H}_{18} \mathrm{O}_{8}$ & 385.0928 & Dihydroferulic acid isomer \\
\hline 60 & 29.50 & $\mathrm{C}_{23} \mathrm{H}_{24} \mathrm{O}_{12}$ & 491.1195 & Glycosylated 3',4',5'-trihydroxy-3,7-dimethylflavone isomer \\
\hline 61 & 29.68 & $\mathrm{C}_{33} \mathrm{H}_{38} \mathrm{O}_{21}$ & 769.1821 & $\begin{array}{l}\text { Apigenin-6-C-beta-galactosyl-8-C-beta-glucosyl-O- } \\
\text { glucuronopyranoside } \\
\text { isomer }\end{array}$ \\
\hline 62 & 30.57 & $\mathrm{C}_{23} \mathrm{H}_{24} \mathrm{O}_{12}$ & 491.1195 & Glycosylated $3^{\prime}, 4^{\prime}, 5^{\prime}$-trihydroxy-3,7-dimethylflavone \\
\hline 63 & 31.57 & $\mathrm{C}_{15} \mathrm{H}_{10} \mathrm{O}_{5}$ & 269.0455 & Apigenin isomer \\
\hline 64 & 32.39 & $\mathrm{C}_{23} \mathrm{H}_{24} \mathrm{O}_{12}$ & 491.1195 & Glycosylated 3',4',5'-trihydroxy-3,7-dimethylflavone isomer \\
\hline 65 & 32.42 & $\mathrm{C}_{15} \mathrm{H}_{10} \mathrm{O}_{5}$ & 269.0455 & Apigenin isomer \\
\hline 66 & 32.70 & $\mathrm{C}_{30} \mathrm{H}_{26} \mathrm{O}_{12}$ & 577.1351 & Procyanidin B-3 isomer \\
\hline 67 & 32.88 & $\mathrm{C}_{20} \mathrm{H}_{18} \mathrm{O}_{8}$ & 385.0928 & Dihydroferulic acid isomer \\
\hline 68 & 33.97 & $\mathrm{C}_{10} \mathrm{H}_{10} \mathrm{O}_{4}$ & 193.0506 & Ferulic acid isomer \\
\hline 69 & 34.00 & $\mathrm{C}_{30} \mathrm{H}_{26} \mathrm{O}_{12}$ & 577.1351 & Procyanidin B-3 isomer \\
\hline 70 & 34.06 & $\mathrm{C}_{26} \mathrm{H}_{28} \mathrm{O}_{14}$ & 563.1395 & $\begin{array}{l}\text { Apigenin-6-C-arabinoside-8-C-hexoside } \\
\text { (Schaftoside/Isoschaftoside) isomer }\end{array}$ \\
\hline 71 & 34.32 & $\mathrm{C}_{21} \mathrm{H}_{22} \mathrm{O}_{8}$ & 401.1241 & Glycosylated pinosylvin isomer \\
\hline 72 & 34.98 & $\mathrm{C}_{20} \mathrm{H}_{18} \mathrm{O}_{8}$ & 385.0928 & Dihydroferulic acid \\
\hline 73 & 35.57 & $\mathrm{C}_{26} \mathrm{H}_{28} \mathrm{O}_{14}$ & 563.1395 & $\begin{array}{l}\text { Apigenin-6-C-arabinoside-8-C-hexoside } \\
\text { (Schaftoside/Isoschaftoside) isomer }\end{array}$ \\
\hline 74 & 36.36 & $\mathrm{C}_{10} \mathrm{H}_{10} \mathrm{O}_{4}$ & 193.0506 & Ferulic acid isomer \\
\hline 75 & 37.14 & $\mathrm{C}_{20} \mathrm{H}_{18} \mathrm{O}_{6}$ & 353.1030 & Hinokinin \\
\hline 76 & 37.28 & $\mathrm{C}_{21} \mathrm{H}_{22} \mathrm{O}_{8}$ & 401.1241 & Glycosylated pinosylvin isomer \\
\hline 77 & 37.37 & $\mathrm{C}_{33} \mathrm{H}_{38} \mathrm{O}_{21}$ & 769.1821 & $\begin{array}{l}\text { Apigenin-6-C-beta-galactosyl-8-C-beta-glucosyl-0- } \\
\text { glucuronopyranoside } \\
\text { isomer }\end{array}$ \\
\hline 78 & 37.82 & $\mathrm{C}_{20} \mathrm{H}_{18} \mathrm{O}_{8}$ & 385.0928 & Dihydroferulic acid isomer \\
\hline 79 & 38.20 & $\mathrm{C}_{30} \mathrm{H}_{26} \mathrm{O}_{12}$ & 577.1351 & Procyanidin B-3 isomer \\
\hline 80 & 38.26 & $\mathrm{C}_{10} \mathrm{H}_{10} \mathrm{O}_{4}$ & 193.0506 & Ferulic acid isomer \\
\hline 81 & 38.38 & $\mathrm{C}_{20} \mathrm{H}_{18} \mathrm{O}_{8}$ & 385.0928 & Dihydroferulic acid isomer \\
\hline 82 & 38.55 & $\mathrm{C}_{22} \mathrm{H}_{26} \mathrm{O}_{8}$ & 417.4390 & Syringaresinol \\
\hline 83 & 39.45 & $\mathrm{C}_{33} \mathrm{H}_{38} \mathrm{O}_{21}$ & 769.1821 & $\begin{array}{l}\text { Apigenin-6-C-beta-galactosyl-8-C-beta-glucosyl-0- } \\
\text { glucuronopyranoside } \\
\text { isomer }\end{array}$ \\
\hline 84 & 39.66 & $\mathrm{C}_{20} \mathrm{H}_{18} \mathrm{O}_{8}$ & 385.0928 & Dihydroferulic acid isomer \\
\hline
\end{tabular}

Anthocyanin

Flavone-C-glycoside

Flavone-C-glycoside

AN AA AB BE BN NO

\section{Anthocyanin}

Flavone

Flavone-C-glycoside

Phenolic acids

Flavone-C-glycoside

Flavone-C-glycoside

Flavone

Lignans

Stilbenoids

Flavone-C-glycoside

Flavone-C-glycoside

BE BO GR

VE

EU IN

MA SI VE

AN BI NO

Flavone-C-glycoside

Anthocyanin

VE

Phenolic acids

Flavone-O-glycoside Flavone-C-glycoside

AB BN

GR MVP

AA AB BN

Flavone-O-glycoside

Flavon

Flavone-O-glycoside

Plavone

BE

GB IN MA MVP

BE GB

Proanthocyanidin

Phenolic acids

Phenolic acids

Proanthocyanidin

Flavone-C-glycoside

Stilbenoids

Phenolic acids

Flavone-C-glycoside

Phenolic acids

Lignan

Stilbenoids

Flavone-C-glycoside

Phenolic acids

Proanthocyanidin

Phenolic acids

Phenolic acids

Lignans

Flavone-C-glycoside

EU GB IN MA MVP

Phenolic acids

$\begin{array}{ll}\text { AN AA FR } & {[16]} \\ \text { BI BN } & {[13]} \\ \text { BN MA } & {[13]} \\ \text { CAN NO } & {[31]} \\ & {[13]} \\ & {[13]} \\ \text { IN } & {[13]} \\ \text { GRM IN } & {[14]} \\ \text { EU FR GB GR GRM IN MA MVP } & {[17]} \\ \text { PA VE } & \\ \text { BE FR } & {[13]} \\ & {[13]}\end{array}$

FR GB MA SI
AB BI BN EU FR GB GR IN MA PA
SI VE

[13]

FR

MA MVP VE

IN $A B$

BR GB GR MA MVP

BI GR

GR

FR GB MVP PA VE

AN AA

GRM VE

AN BN BI BO EU FR GB GR IN MA MVP NO PA SI VE

$\mathrm{AABE}$

13]

BN CAR EU MA

GRM IN VE

MVP PA

[13]

AN BN BI BO CAR EU FR GR GRM

IN MA MI PA SI VE

BI FR GR MVP

AA BN BE BO CAN GRM MA MI

NO PA

BI EU IN MVP SI VE

GB IN MA NO PA

EU GB MVP PA

$\left.\begin{array}{l}{[13]} \\ {[13]} \\ {[13} \\ {[13} \\ {[32} \\ {[31} \\ {[31} \\ {[32]} \\ {[13]} \\ {[17} \\ {[31]} \\ {[13]} \\ {[31]} \\ {[14} \\ 17 \\ {[13} \\ \\ {[31]} \\ {[32}\end{array}\right]$

BO CAR EU FR IN MVP MI PA VE 
Table 3 (Continued)

\begin{tabular}{|c|c|c|c|c|c|c|c|c|}
\hline \multirow[t]{2}{*}{ No. } & \multirow{2}{*}{$\begin{array}{l}\text { Retention } \\
\text { time (min) }\end{array}$} & \multirow{2}{*}{$\begin{array}{l}\text { Molecular } \\
\text { formula }\end{array}$} & \multirow[t]{2}{*}{$\mathrm{m} / \mathrm{z}$ calculated } & \multirow[t]{2}{*}{ Compound } & \multirow[t]{2}{*}{ Class } & \multicolumn{2}{|l|}{ Sample } & \multirow[t]{2}{*}{ Reference } \\
\hline & & & & & & Free extract & Bound extract & \\
\hline 85 & 40.02 & $\mathrm{C}_{20} \mathrm{H}_{18} \mathrm{O}_{8}$ & 385.0928 & Dihydroferulic acid isomer & Phenolic acids & & $\begin{array}{l}\text { AA EU FR GB GR GRM IN MA MI } \\
\text { PA VE }\end{array}$ & [31] \\
\hline 86 & 40.25 & $\mathrm{C}_{30} \mathrm{H}_{26} \mathrm{O}_{12}$ & 577.1351 & Procyanidin B-3 & Proanthocyanidin & & EU FR GB MA MVP NO SI & [32] \\
\hline 87 & 41.01 & $\mathrm{C}_{22} \mathrm{H}_{26} \mathrm{O}_{8}$ & 417.4390 & Syringaresinol isomer & Lignans & & GB VE & [14] \\
\hline 88 & 42.20 & $\mathrm{C}_{30} \mathrm{H}_{26} \mathrm{O}_{12}$ & 577.1351 & Procyanidin B-3 isomer & Proanthocyanidin & & FR GB SI & [32] \\
\hline 89 & 43.63 & $\mathrm{C}_{33} \mathrm{H}_{38} \mathrm{O}_{21}$ & 769.1821 & $\begin{array}{l}\text { Apigenin-6-C-beta-galactosyl-8-C-beta-glucosyl-0- } \\
\text { glucuronopyranoside } \\
\text { isomer }\end{array}$ & Flavone-C-glycoside & & FR VE & [13] \\
\hline 90 & 44.00 & $\mathrm{C}_{20} \mathrm{H}_{18} \mathrm{O}_{8}$ & 385.0928 & Dihydroferulic acid isomer & Phenolic acids & & AA AB BE FR MVP VE & [31] \\
\hline 91 & 44.06 & $\mathrm{C}_{10} \mathrm{H}_{10} \mathrm{O}_{4}$ & 193.0506 & Ferulic acid isomer & Phenolic acids & & AA BO GR & [31] \\
\hline 92 & 44.37 & $\mathrm{C}_{33} \mathrm{H}_{38} \mathrm{O}_{21}$ & 769.1821 & $\begin{array}{l}\text { Apigenin-6-C-beta-galactosyl-8-C-beta-glucosyl-0- } \\
\text { glucuronopyranoside } \\
\text { isomer }\end{array}$ & Flavone-C-glycoside & & FR VE & [13] \\
\hline 93 & 44.85 & $\mathrm{C}_{20} \mathrm{H}_{22} \mathrm{O}_{6}$ & 357.1343 & Pinoresinol & Lignans & CAR & $\begin{array}{l}\text { BN CAR FR GB GR GRM IN MI NO } \\
\text { SI VE }\end{array}$ & [14] \\
\hline 94 & 45.28 & $\mathrm{C}_{15} \mathrm{H}_{10} \mathrm{O}_{5}$ & 269.0455 & Apigenin isomer & Flavone & BE CAR GB SI & BI BN CAR EU IN & [13] \\
\hline 95 & 45.37 & $\mathrm{C}_{26} \mathrm{H}_{28} \mathrm{O}_{14}$ & 563.1395 & $\begin{array}{l}\text { Apigenin-6-C-arabinoside-8-C-hexoside } \\
\text { (Schaftoside/Isoschaftoside) isomer }\end{array}$ & Flavone-C-glycoside & & $\mathrm{AB}$ & [13] \\
\hline 96 & 45.85 & $\mathrm{C}_{17} \mathrm{H}_{14} \mathrm{O}_{7}$ & 329.0666 & 5,7,4'-trihydroxy-3',5'-dimethoxy-flavone (tricin) & Flavone & $\begin{array}{l}\text { CAN CAR EU GB GR } \\
\text { GRM NO }\end{array}$ & CAR EU GRM MI PA & [13] \\
\hline 97 & 46.65 & $\mathrm{C}_{15} \mathrm{H}_{11} \mathrm{O}_{6} \mathrm{Cl}$ & 323.2870 & Anthocyanidin (cyanidin chloride) & Anthocyanidin & MA & CAN EU MI & [16] \\
\hline 98 & 46.98 & $\mathrm{C}_{33} \mathrm{H}_{38} \mathrm{O}_{21}$ & 769.1821 & $\begin{array}{l}\text { Apigenin-6-C-beta-galactosyl-8-C-beta-glucosyl-0- } \\
\text { glucuronopyranoside } \\
\text { isomer }\end{array}$ & Flavone-C-glycoside & & EU FR IN & [13] \\
\hline 99 & 47.02 & $\mathrm{C}_{26} \mathrm{H}_{28} \mathrm{O}_{14}$ & 563.1395 & $\begin{array}{l}\text { Apigenin-6-C-arabinoside-8-C-hexoside } \\
\text { (Schaftoside/Isoschaftoside) isomer }\end{array}$ & Flavone-C-glycoside & & $\mathrm{AB} B \mathrm{BO}$ & [13] \\
\hline 100 & 47.59 & $\mathrm{C}_{23} \mathrm{H}_{24} \mathrm{O}_{9}$ & 443.1347 & Formononetin (Glycosylated and methylated) & Isoflavone & GB & GB MA PA & [17] \\
\hline 101 & 48.58 & $\mathrm{C}_{23} \mathrm{H}_{24} \mathrm{O}_{9}$ & 443.1347 & Formononetin (Glycosylated and methylated) isomer & Isoflavone & GR MA MI VE & & [17] \\
\hline 102 & 48.67 & $\mathrm{C}_{30} \mathrm{H}_{26} \mathrm{O}_{12}$ & 577.1351 & Procyanidin B-3 isomer & Proanthocyanidin & & GB MA & [32] \\
\hline 103 & 49.46 & $\mathrm{C}_{23} \mathrm{H}_{24} \mathrm{O}_{9}$ & 443.1347 & Formononetin (Glycosylated and methylated) isomer & Isoflavone & AN GB MA NO VE & & [17] \\
\hline 104 & 49.90 & $\mathrm{C}_{23} \mathrm{H}_{24} \mathrm{O}_{9}$ & 443.1347 & Formononetin (Glycosylated and methylated) isomer & Isoflavone & AN MA MVP VE & & [17] \\
\hline
\end{tabular}

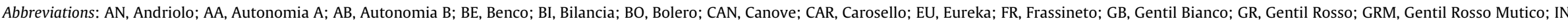
Inallettabile; MA, Marzuolo d'Aqui; MVP, Marzuolo Val Pusteria; MI, Mieti; NO, Nobel; PA, Palesio; SI, Sieve; VE, Verna. 
a) Syringic acid<smiles>COc1cc(C(=O)O)cc(OC)c1O</smiles>

d) $p$-Coumaric acid<smiles>O=C(O)/C=C/c1ccc(O)cc1</smiles>

g) Vicenin-2 (apigenin-6,8-di-C-glucoside)<smiles>O=C1C=C(c2ccc(O)cc2)OC2C(C3O[C@H](CO)[C@@H](O)[C@H](O)[C@H]3O)=C(O)C(C3O[C@H](CO)[C@@H](O)[C@H](O)[C@H]3O)=C(O)C12</smiles>

b) Vanillin<smiles>COc1cccc(C=O)c1O</smiles>

c) Pinosylvin<smiles>Oc1cc(O)cc(/C=C/c2ccccc2)c1</smiles>
e) Apigenin
f) Schaftoside<smiles>O=C1C=C(c2ccc(O)cc2)OC2C=C(O)C=C(O)C12</smiles>

Fig. 2. Structural formulae of representative phenolic compounds detected in the wheat genotypes.

both free and bound forms; however, it is chiefly abundant in the aleurone layer cross-linked with cell wall components (i.e. arabinoxylans) via ester and ether bonds [34]. Ferulic acid was previously described in wheat grains along with other benzoic and cinnamic acid derivatives as dihydroferulic, sinapic, caffeic, vanillic, syringic, p-coumaric and p-hydroxybenzoic acids [7,12,18,20,31]. In our study dihydroferulic (isomer compounds $59,67,72,78$, $81,84,85,90$ ), ferulic (isomer compounds $2,3,38,41,49,68$, $74,80,91$ ), syringic (isomer compounds 1 and 6), vanillic (isomer compounds 4 and 10) and p-coumaric acid (compound 33) were detected in most of the investigated varieties, mainly in the bound fractions. $p$-hydroxybenzaldehyde (compound 8), vanillin (compound 29) and syringaldehyde (compound 34) were found in the bound extracts of some of the analyzed genotypes. Moreover, the old wheat variety Carosello showed the presence of compound 42 with mass $224.0612\left(\mathrm{C}_{11} \mathrm{H}_{12} \mathrm{O}_{5}\right)$ in the bound extract, tentatively identified as sinapic acid. Vanillin was recorded in six old wheat varieties (Canove, Carosello, Gentil Rosso Mutico, Inallettabile, Marzuolo d'Aqui, Sieve) and in the modern cultivar Eureka. This finding is intriguing for the development of wheat-based food with peculiar sensory features since, even at low concentrations, vanillin contributes to the flavor and aroma properties of wheat flours and derived foods (bread and bakery products) [35].

\subsubsection{Flavonoids}

Flavonoids are a large class of phenolic compounds with a C6-C3-C6 skeleton and consist of two aromatic rings joined by a three-carbon bridge. Several studies reported on the healthpromoting effects of flavonoids as antioxidant, anticancer, antiallergic, anti-inflammatory, anticarcinogenic and gastroprotective agents [36-38]. Flavonoids are classified in different classes according to diverse chemical structures and characteristics, including flavonols, flavones, flavonones, anthocyanidins and isoflavones. In wheat grains, flavonoids are mainly located in the pericarp layers and exist in the free and bound forms, usually occurring as glycosides [8,21]. In our study, flavones resulted the most representative flavonoid group of the investigated wheat grains, comprising of 2 aglyconic forms, $9 \mathrm{C}$-glycosylated and 20 -glycosylated compounds. In wheat, the glycosidic forms are mainly apigenin $\left(5,7,4^{\prime}-\right.$ trihydroxyflavone) and luteolin (5,7,3', $4^{\prime}$-tetrahydroxyflavone) derivatives and accumulate as their respective $6-C$ and/or 8$C$-glycosidic conjugates $[13,17]$. The interpretation of the mass spectra allowed the detection of two aglyconic flavones, identified in the free and bound extracts of the wheat genotypes as apigenin (isomer compounds 47, 52, 63, 65, 94) with mass $270.0455\left(\mathrm{C}_{15} \mathrm{H}_{10} \mathrm{O}_{5}\right)$ and 5,7,4'-trihydroxy-3',5'-dimethoxyflavone (tricin) (compound 96) with mass $330.0666\left(\mathrm{C}_{17} \mathrm{H}_{14} \mathrm{O}_{7}\right)$. In common with previous studies, lucenin-1/3 (luteolin-6/8- 
$C$-xyloside-8/6-C-glucoside) (isomer compounds 9, 12, 16, 18), vicenin-2 (apigenin-6,8-di-C-glucoside) (isomer compounds 5,7 , $11,13,15,20,24,27,32,39,40$ ), apigenin-6-C-beta-galactosyl8 -C-beta-glucosyl-O-glucuronopyranoside (isomer compounds 44 , $45,56,61,77,83,89,92,98)$, methylisoorientin- $2^{\prime \prime}$-O-rhamnoside (isomer compounds 50,55), vitexin/isovitexin (isomer compounds $37,48)$ and apigenin-6-C-arabinoside-8-C-hexoside (schaftoside/isoschaftoside) (isomer compounds 14, 17, 19, 22, 23, 27, 70, $73,95,99)$ were found in most of the investigated wheat genotypes, both in free and bound fractions (Table 3 ). Compound 21 with molecular mass $625.1411\left(\mathrm{C}_{27} \mathrm{H}_{30} \mathrm{O}_{17}\right)$ was tentatively identified as apigenin-6/8-C-pentoside-8/6-C-hexoside and detected only in the bound extract of the modern variety Bilancia. Compounds 51 and 57 , identified as isovitexin- $2^{\prime \prime}-O$-rhamnoside $\left(\mathrm{C}_{27} \mathrm{H}_{30} \mathrm{O}_{14}\right.$, mass 578.1562$)$ and orientin/isoorientin $\left(\mathrm{C}_{21} \mathrm{H}_{20} \mathrm{O}_{11}\right.$, mass 448.3800), respectively, were found exclusively in the free fraction of the old genotype Verna. Two flavone-O-glycosides were found in the free and bound extracts of the wheat samples, with masses 492.1195 and 534.1300, putatively identified as glycosylated $3^{\prime}, 4^{\prime}, 5^{\prime}$-trihydroxy-3,7-dimethylflavone (isomer compounds $60,62,64)$ and glycosylated and acetylated $3^{\prime}, 4^{\prime}, 5^{\prime}$-trihydroxy-3,7dimethylflavone (isomer compounds $25,28,36$ ), respectively. All the flavones detected in the free and bound extracts of the 22 common wheat varieties were previously described in wheat bran and whole grains $[13,17,39]$. Isoflavones are part of the flavonoid group with the B-ring attached at $\mathrm{C} 3$ rather than the $\mathrm{C} 2$ position. These secondary metabolites have been widely investigated in leguminous plants (i.e. soybean), in which they occur in high concentrations, mainly as daidzein and genistein derivative compounds [40]. Matus-Cádiz et al. [17] reported on the presence of formononetin (the glycosilated and methylated daidzein derivative) in wheat. In our study, compound 100 and relating isomers $(101,103,104)$ with mass $443.1347\left(\mathrm{C}_{23} \mathrm{H}_{24} \mathrm{O}_{9}\right)$, tentatively identified as formonotenin, were detected in the free and bound extracts of 9 wheat varieties (Table 3 ).

Anthocyanidins are secondary metabolites belonging to the flavonoid class and playing an important physiological role in UV protection of plant tissues. Moreover, several studies reported on the health-promoting effects of anthocyanidins as antioxidants and anti-inflammatory compounds $[16,41,42]$. In wheat, anthocyanidins are found in different parts of the plant (coleoptile, culm, leaves) and in the pericarp and aleurone layer of the caryopsis. Although in common wheat grains pigments are generally present at very low concentration, they were detected in higher amounts in the outer layers of blue, purple and red wheat cultivar kernels $[15,16,43,44]$. Wheat anthocyanidins are mainly found as cyanidin, peonidin and pelargonidin derivatives in the glycosylated forms (anthocyanins), linked with glucose, galactose and arabinose [16]. Compound 46 with mass 434.2710 and deduced molecular formula $\mathrm{C}_{21} \mathrm{H}_{21} \mathrm{O}_{10} \mathrm{Cl}$ was found in the bound extracts of Andriolo, Autonomia A and Frassineto varieties and assigned as pelargonidin-3-glucoside (callistephin). A cyanidin glycosylated derivative (mass $448.0932, \mathrm{C}_{21} \mathrm{H}_{21} \mathrm{O}_{11} \mathrm{Cl}$ ) was detected in the free and bound extracts of few old genotypes and putatively identified as cyanidin-3-glucoside (kuromanin) (compound 58). Peonidin3-glucoside (compound 43), with mass 462.1089 and deduced molecular formula $\mathrm{C}_{22} \mathrm{H}_{23} \mathrm{O}_{11} \mathrm{Cl}$, was found exclusively in the free phenolic fraction of the old variety Sieve. Along with anthocyanins, an anthocyanidin aglycone was detected in the wheat varieties Canove, Eureka, Marzuolo d'Aqui and Mieti and identified as cyanidin chloride (mass 324.2870, $\mathrm{C}_{15} \mathrm{H}_{11} \mathrm{O}_{6} \mathrm{Cl}$ ) (compound 97).

\subsubsection{Other chemical classes (coumarins, stilbenes, proanthocyanidins, lignans)}

Besides phenolic acids and flavonoids which are the most representative and investigated polyphenol classes, whole wheat grains contain different phenolic compounds belonging to the groups of coumarins, stilbenes, proanthocyanidins and lignans.

Coumarins are a class of lactones with a $2 \mathrm{H}$-1-benzopyran2-one nucleus. These phenolic compounds are used clinically as antineoplastic and for the treatment of lymphedema and venous insufficiency $[45,46]$. Coumarin (1,2-benzopyrone) represents the simplest compound of the class, consisting of an aromatic ring fused to a condensed lactone ring, and possesses aroma properties. Previous studies described the presence of coumarins in common wheat caryopses in the free, carboxylated and hydroxylated forms [31]. Compound 31 with mass 146.0295 and deduced molecular formula $\mathrm{C}_{9} \mathrm{H}_{6} \mathrm{O}_{2}$ was tentatively identified as coumarin. It was detected exclusively in the bound extracts of Gentil Rosso Mutico and Marzuolo d'Aqui, thus representing a peculiarity of the two old genotypes.

Stilbenes are a small family of phenolics implicated in plant disease resistance, thus classified as phytoalexins. These secondary metabolites act as natural protective agents against pests and diseases as they possess antiviral, antifungal and antimicrobial activity, and their production increases in case of biotic and abiotic stresses. In addition, numerous studies investigated the pharmacological activity of stilbenes, in particular the antioxidant, anti-inflammatory and anticarcinogenic effects of resveratrol and pinosylvin [47-51]. Although very few studies reported on stilbene occurrence in wheat, two pinosylvin derivatives were described by Matus-Cádiz et al. [17]. The glycosylated form of pinosylvin (mass 402.1241, $\mathrm{C}_{21} \mathrm{H}_{22} \mathrm{O}_{8}$ ) was assigned as compound 54 (isomer forms 71,76 ) and detected in the bound extracts of 10 investigated wheat varieties. Isomer compounds 30 and 35 with mass 536.1821 and deduced molecular formula $\mathrm{C}_{26} \mathrm{H}_{32} \mathrm{O}_{12}$ were tentatively identified as double glycosylated pinosylvin and detected exclusively in the free and bound extracts of the old wheat variety Gentil Rosso.

Proanthocyanidins are a class of colorless phenolics characterized by an oligomeric or polymeric structure, based on flavanol units. Several studies demonstrated the proanthocyanidin health benefits due to their antioxidant activity, modulation of immune function and anti-thrombotic effect [52,53]. Catechin and epicatechin are the constitute units of procyanidins, a group of proanthocyanidins described previously in red-grained wheat bran [32]. Compound 86 (isomer forms 69, 79, 88, 102) with mass 578.1351 and deduced molecular formula $\mathrm{C}_{30} \mathrm{H}_{26} \mathrm{O}_{12}$ was assigned as procyanidin $\mathrm{B}-3$ and detected in the bound extracts of the wheat genotypes.

Lignans are a group of phenolics classified as phytoestrogens. Although they are non-steroidal compounds, lignans are structurally similar to endogenous estrogens and exhibit anticancerogenic, antioxidant, anti-proliferative, pro-apoptotic and antiangiogenic properties [54]. As reported in our previous study, different lignan compounds are present in wheat whole grains, with a total amount ranging from 2.6 to $5.0 \mu \mathrm{g}$ per gram of dry weight [14]. Compound 75 with mass 353.1030 and deduced molecular formula $\mathrm{C}_{20} \mathrm{H}_{18} \mathrm{O}_{6}$ was tentatively identified as hinokinin and detected in the bound extracts of Bianco Nostrale, Carosello, Eureka and Marzuolo d'Aqui varieties. Two other lignan compounds were identified both in the free and bound extracts of the wheat samples and assigned as syringaresinol (isomer compounds 53, 82, 87) with mass $417.4390\left(\mathrm{C}_{22} \mathrm{H}_{26} \mathrm{O}_{8}\right)$ and pinoresinol (compound 93) with mass $357.1343\left(\mathrm{C}_{20} \mathrm{H}_{22} \mathrm{O}_{6}\right)$.

\subsection{Phenolic profiles of old and modern wheat varieties}

On the basis of the similarity among each phytochemical profile, the 16 old wheat genotypes were classified in two groups as indicated in Table 4 and compared to the 6 modern wheat varieties. The number of detected free polyphenols resulted significantly higher in group 2 containing the old varieties Bianco Nostrale, Frassineto, 
Table 4

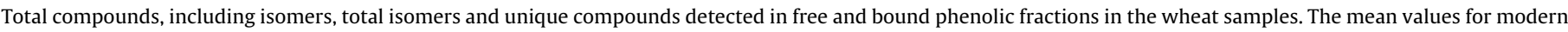
and old varieties (group1, group 2) are reported.

\begin{tabular}{|c|c|c|c|c|c|c|}
\hline \multirow[t]{2}{*}{ Cultivar } & \multicolumn{3}{|l|}{ Free phenolic } & \multicolumn{3}{|l|}{ Bound phenolic } \\
\hline & Total compounds ${ }^{\mathrm{a}}$ & Total isomers & Unique compounds & Total compounds ${ }^{\mathrm{a}}$ & Total isomers & Unique compounds \\
\hline Modern varieties & $3.5(\mathrm{~b})^{\mathrm{b}}$ & $0.8(\mathrm{~b})$ & $0.2(\mathrm{a})$ & $13.3(b)$ & 4.5 (b) & 0.3 (a) \\
\hline Old varieties (group 1) & $5.8(\mathrm{ab})$ & $2.1(\mathrm{ab})$ & $0.2(\mathrm{a})$ & 12.3 (b) & 4.0 (b) & $0.2(\mathrm{a})$ \\
\hline Old varieties (group 2) & $11.0(a)$ & $5.1(\mathrm{a})$ & $0.6(a)$ & $18.6(\mathrm{a})$ & $7.0(a)$ & $0.5(a)$ \\
\hline
\end{tabular}

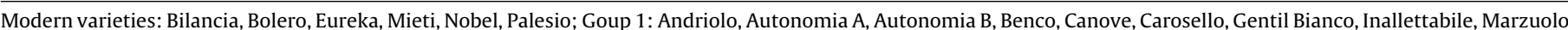
Val Pusteria, Sieve; Group 2: Bianco Nostrale, Frassineto, Gentil Rosso, Gentil Rosso Mutico, Marzuolo d'Aqui, Verna.

a Including isomers.

b Means followed by the same letter or no letter are not significantly different for $P<0.05$.

Gentil Rosso, Gentil Rosso Mutico, Marzuolo d'Aqui and Verna (11.0) than those found in the modern cultivars (3.5). Moreover the mean number of isomer forms was approximately six times higher in group 2 (5.1) than in modern genotypes (0.8). No significant differences were observed between group 1 and modern cultivars, in terms of both total polyphenols and isomer forms. As regards the bound fraction, not statistically different mean values were observed for modern and group 1 varieties (13.3 and 12.3 phenolic compounds, respectively). Group 2 showed a mean value of bound phenolics (18.6) and isomer forms (7.0) significantly higher than all the other investigated genotypes. The interpretation of the mass spectra highlighted the presence of phenolic compounds detected exclusively in some of the investigated genotypes. However, no significant differences were found as regards the mean number of unique compounds among the three groups, both for free and bound fractions. To show the relationships among the investigated wheat genotypes, the whole set of data was elaborated for the correspondence analysis as indicated in the biplot of Fig. 3. In the biplot six old varieties (Gentil Bianco, Gentil Rosso, Frassineto, Marzuolo d'Aqui, Marzuolo Val Pusteria, Verna) formed a separated cluster that can be associated with apigenin-6-C-arabinoside-8-Chexoside (compound 23), vicenin-2 (apigenin-6,8-di-C-glucoside) (compound 40), glycosylated pinosylvin (compound 54), dihydroferulic acid (compound 72) and procyanidin B-3 (compound 86).
The six old genotypes were characterized by an elevated number of isomer forms for all these compounds. Moreover, in this cluster, the presence of unique compounds influenced the position of the old varieties Gentil Rosso (double glycosilated pinosylvin, compound 30) and Verna (isovitexin-2"-O-rhamnoside, compound 51 and orientin/isoorientin, compound 57). Another group, clustering in the North-East quadrant of the plot, included both old and modern varieties (Andriolo, Autonomia A, Autonomia B, Bolero, Canove, Mieti, Nobel) sharing the presence of phenolic acids as syringic acid (compound 6), p-coumaric acid (compound 33) and syringaldehyde (compound 34). The old varieties Andriolo, Autonomia A and Canove were positioned in the upper part of the quadrant probably due to the common presence of pelargonidin-3-glucoside (compound 46). The modern cultivar Palesio and the old variety Gentil Rosso Mutico occupied an intermediated position between two clusters previously described, indicating similarities with both groups. The position of three old (Bianco Nostrale, Benco, Carosello) and one modern varieties (Eureka) in the South-East quadrant, did not form a compact cluster. However, this could be ascribed to the high number of isomers for compound 47 (apigenin) and the common presence of vanillic acid (compound 4) and hinokinin (compound 75). Sinapic acid (compound 42), detected exclusively in the old variety Carosello, affected the separated position of the wheat genotype within the South-East

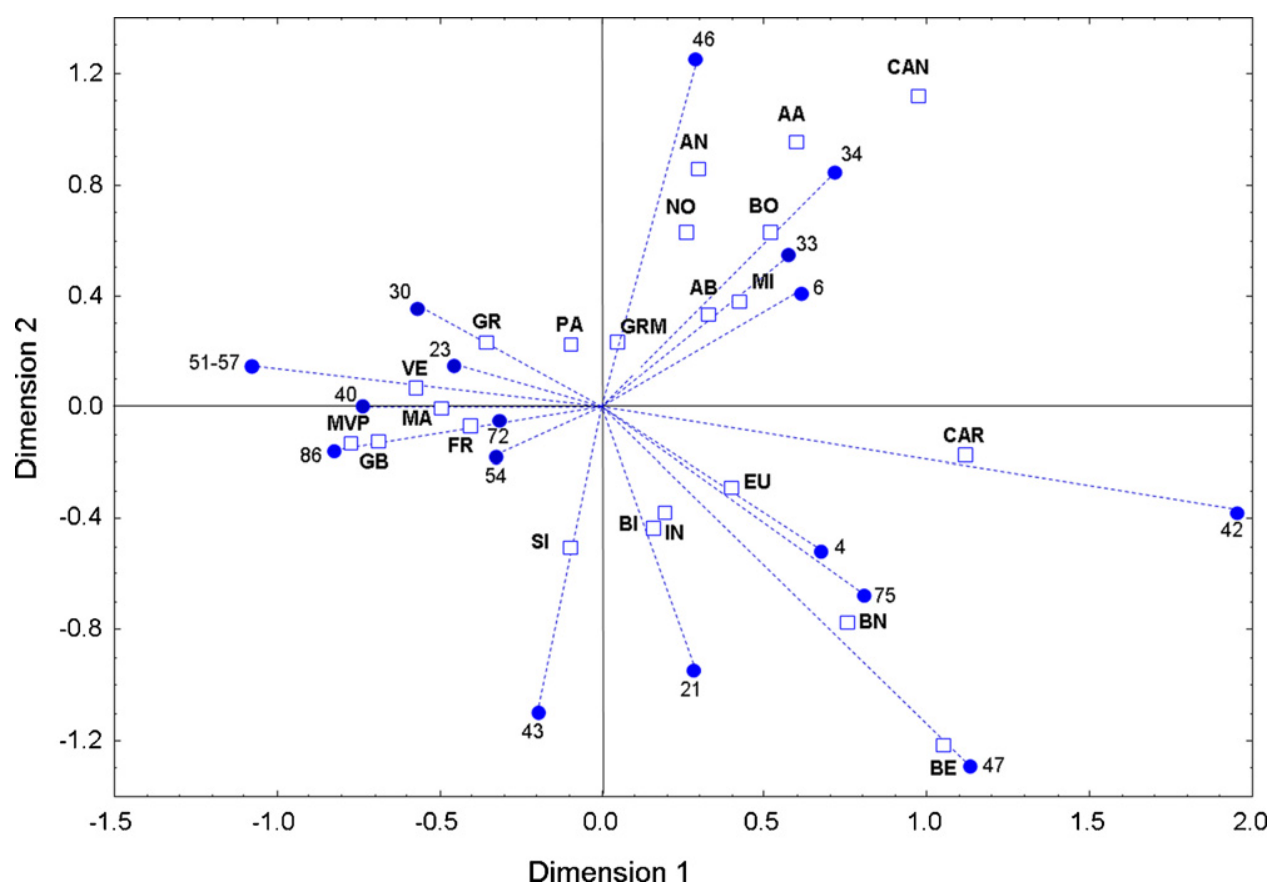

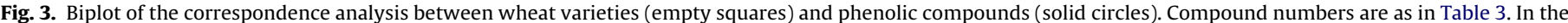

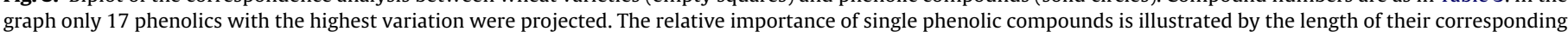
centrifugal lines (dotted lines). 
quadrant. The modern variety Bilancia and ancient genotypes Sieve and Inallettabile were placed in an intermediate position between the cluster of Gentil Bianco and that of Bianco Nostrale. The Sieve position was strongly influenced by the presence of peonidin-3-glucoside (compound 43) as unique compound, while apigenin-6/8-C-pentoside-8/6-C-hexoside (compound 21) highly affected the relative position of Inallettabile and Bilancia.

\section{Concluding remarks}

The present work aimed at giving a pioneering insight on the phenolic-based phytochemical composition of old and modern common wheat varieties from Italy. By using a powerful HPLC-ESI-TOF-MS analytical method, a total of 104 compounds (including isomer forms) have been separated and tentatively identified in the free and bound phenolic fractions of whole grains. The obtained metabolomic fingerprints showed the presence of several classes of health-promoting compounds, phenolic acids and flavonoids being the most representative groups, along with coumarins, stilbenes, proanthocyanidins and lignans.

Remarkable quantitative and qualitative differences were detected among the 16 old and the 6 modern investigated wheat genotypes. The highest total polyphenol content was detected in the old variety Verna, followed by other three old genotypes, Gentil Rosso, Gentil Rosso Mutico, Marzuolo d'Aqui, and the two modern cultivars Nobel and Eureka. A high variability among genotypes was also observed for the total flavonoid content: Verna, Gentil Rosso, Gentil Rosso Mutico and Marzuolo d'Aqui, along with the old genotypes Inallettabile and Sieve were the richest varieties, whereas among the modern ones, Eureka and Nobel showed again the highest amounts.

As regards the qualitative phenolic composition the fingerprints of most of the old genotypes revealed the presence of a number of total compounds and total isomers much higher than that identified in the modern cultivars, confirming that ancient grains may represent a rich source of biodiversity, especially as regards phenolic compounds. The present findings may be successfully used in breeding programs for developing bread wheat varieties with added value in terms of health-promoting phytochemicals.

\section{Acknowledgments}

The authors are grateful to the Spanish Ministry of Education and Science for the project AGL2008-05108-C03-03/ALI and to Andalusian Regional Government Council of Innovation and Science for the excellence projects P07-AGR-02619, P09-CTS-4564 and P10FQM-6563 projects. Authors wish also to acknowledge the Emilia Romagna region, Italy (Project "BioPane", CUP J31J09000430002) and the Italian Ministry of Agriculture (Project "Pane della salute" MiPAF-OIGA, CUP J31J09000370001) for financially supporting the research.

\section{References}

[1] L.U. Thompson, Crit. Rev. Food Sci. Nutr. 34 (1994) 473.

[2] S. Liu, M.J. Stampfer, F.B. Hu, E. Giovannucci, E. Rimm, J.E. Manson, C.H. Hennekens, Am. J. Clin. Nutr. 70 (1999) 412.
[3] D.R. Jacobs, H.E. Meyer, K. Solvoll, Eur. J. Clin. Nutr. 55 (2001) 137.

[4] J.W. Carter, R. Madl, F. Padula, Nutr. Res. 26 (2006) 33.

[5] A. Fardet, Nutr. Res. Rev. 23 (2010) 65.

[6] L. Yu, S. Haley, J. Perret, M. Harris, J. Wilson, M. Qian, J. Agric. Food Chem. 50 (2002) 1619.

[7] K.K. Adom, M.E. Sorrells, R.H. Liu, J. Agric. Food Chem. 51 (2003) 7825.

[8] K.K. Adom, M.E. Sorrells, R.H. Liu, J. Agric. Food Chem. 53 (2005) 2297.

[9] N. Okarter, C.S. Liu, M.E. Sorrells, R.H. Liu, Food Chem. 119 (2010) 249

[10] H. Wu, T. Haig, J. Pratley, D. Lemerle, M. An, J. Chromatogr. A 864 (1999) 315.

[11] C. Cavaliere, P. Foglia, E. Pastorini, R. Samperi, A. Laganà, Rapid Commun. Mass Spectrom. 19 (2005) 3143.

[12] C. Gallardo, L. Jiménez, M.T. Garcia-Conesa, Food Chem. 99 (2006) 455

[13] R.E. Asenstorfer, Y. Wang, D.J. Mares, J. Cereal Sci. 43 (2006) 108.

[14] G. Dinelli, I. Marotti, S. Bosi, S. Benedettelli, L. Ghiselli, S. Cortacero-Ramirez, A Carrasco-Pancorbo, A. Segua-Carretero, A. Fernandez-Gutierrez, Electrophoresis 28 (2007) 4212 .

[15] C. Hu, Y.Z. Cai, W. Li, H. Corke, D.D. Kitts, Food Chem. 104 (2007) 955.

[16] F.S. Hosseinian, W. Li, T. Beta, Food Chem. 109 (2008) 916.

[17] M.A. Matus-Cádiz, T.E. Daskalchuk, B. Verma, D. Puttick, R.N. Chibbar, G.R. Gray, C.E. Perron, R.T. Tyler, P. Hucl, J. Agric. Food Chem. 56 (2008) 1644

[18] P. Mattila, J.M. Pihlava, J. Hellstrom, J. Agric. Food Chem. 53 (2005) 8290.

[19] B. Verma, P. Hucl, R.N. Chibbar, Food Chem. 116 (2009) 947.

[20] K.H. Kim, R. Tsao, R. Yang, S.W. Cui, Food Chem. 95 (2006) 466

[21] P.V. Hung, T. Maeda, K. Miyatake, N. Morita, Food Res. Int. 42 (2009) 185.

[22] G. Dinelli, A. Segura Carretero, R. Di Silvestro, I. Marotti, S. Fu, S. Benedettelli, L. Ghiselli, A. Fernandez-Gutierrez, J. Chromatogr. A 1216 (2009) 7229.

[23] L. Yu, S. Haley, J. Perret, M. Harris, Food Chem. 86 (2004) 11

[24] J. Moore, J.G. Liu, K. Zhou, L. Yu, J. Agric. Food Chem. 54 (2006) 5313.

[25] A. Mpofu, H.D. Sapirstein, T. Beta, J. Agric. Food Chem. 54 (2006) 1265

[26] M. Vaher, K. Matso, T. Levandi, K. Helmja, M. Kaljurand, Procedia Chem. 2(2010) 76.

[27] V.L. Singleton, R. Orthofer, R.M. Lamuela-Raventos, Meth. Enzym. 299 (1999) 152.

[28] J.P. Benzecri, L'analyse des données, Tome 2: L'Analyse des Correspondances, Dunod, Paris, 1973.

[29] P.V. Hung, D.W. Hatcher, W. Barker, Food Chem. 126 (2011) 1896.

[30] C.M. Liyana-Pathirana, F. Shahidi, J. Agric. Food Chem. 54 (2006) 1256

[31] J. Lachman, J. Dudjak, M. Orsak, V. Pivec, Plant Soil Environ. 49 (2003) 1.

[32] J.A. McCallum, J.R.L. Walker, Cereal Chem. 67 (1989) 282.

[33] S. Irmak, R.S. Jonnala, F. MacRitchie, J. Cereal Sci. 48 (2008) 20

[34] A.U. Buranov, G. Mazza, Food Chem. 115 (2009) 1542.

[35] P.J. Wood, in: E.-S.M. Abdel-Aal, P.J. Peter (Eds.), Specialty Grains for Food and Feed, AACC, St. Paul, MN, 2005, p. 367.

[36] N.C. Cook, S. Samman, J. Nutr. Biochem. 7 (1996) 66

[37] J.B. Harborne, C.A. Williams, Phytochemistry 55 (2000) 481.

[38] L.H. Yao, Y.M. Jiang, J. Shi, F.A. Tomas-Barberan, N. Datta, R. Singanusong, S.S. Chen, Plant Food Hum. Nutr. 59 (2004) 113

[39] Y. Feng, C.E. Mc Donald, B.A. Vick, Cereal Chem. 65 (1998) 452.

[40] K. Mitani, S. Narimatsu, H. Kataoka, J. Chromatogr. A 986 (2003) 169.

[41] C. Manach, A. Scalbert, C. Morand, C. Rémèsy, L. Jiménez, Am. J. Clin. Nutr. 79 (2004) 727

[42] R.L. Prior, L. Gu, Phytochemistry 66 (2005) 2264

[43] E-S.M. Abdel-Aal, P. Hucl, J. Agric. Food Chem. 51 (2003) 2174.

[44] M.T. Escribano-Bailon, C. Santos-Buelga, J.C. Rivas-Gonzalo, J. Chromatogr. A 1054 (2004) 129.

[45] J.R. Casley-Smith, Int. Angiol. 18 (1999) 31.

[46] S.P. Felter, J.D. Vassallo, B.D. Carlton, G.P. Daston, Food Chem. Toxicol. 44 (2006) 462.

[47] D.G. Soares, A.C. Andreazza, M.J. Salvador, J. Agric. Food Chem. 51 (2003) 1077.

[48] F. Wolter, A. Clausnitzer, B. Akoglu, J. Stein, J. Nutr. 132 (2002) 298

[49] S.H. Lee, N.H. Shin, S.H. Kang, J.S. Park, S.R. Chung, K.R. Min, Y. Kim, Planta Med. 64 (1998) 204.

[50] K. Huang, S. Zhou, M. Lin, Y. Wang, Planta Med. 68 (2002) 916.

[51] E.J. Park, H.Y. Min, Y.H. Ahn, C.M. Bae, J.H. Pyee, S.K. Lee, Bioorg. Med. Chem. Lett. 14 (2004) 5895.

[52] J.F. Hammerstone, S.A. Lazarus, H.H. Schmitz, J. Nutr. 130 (2000) $2086 \mathrm{~S}$

[53] T. Sano, E. Oda, T. Yamashita, A. Naemura, Y. Ijiri, J. Yamakoshi, J. Yamamoto, Thromb. Res. 115 (2005) 115.

[54] A.L. Webb, M.L. McCullough, Nutr. Cancer 51 (2005) 117 